\title{
Osteogenesis imperfecta type 5
}

INSERM

\section{Source}

INSERM. (1999). Orphanet: an online rare disease and orphan drug data base.

Osteogenesis imperfecta type 5. ORPHA:216828

Osteogenesis imperfecta type $\mathrm{V}$ is a moderate type of osteogenesis imperfecta (Ol; see this term), a genetic disorder characterized by increased bone fragility, low bone mass and susceptibility to bone fractures with variable severity. OI type $V$ is characterized by mild to moderate short stature, dislocation of the radial head, mineralized interosseous membranes, hyperplasic callus, white sclera and no dentinogenesis imperfecta (DI; see this term). 